\title{
PROBLEMS AND PROGRESS IN VIRAL CHEMOTHERAPY
}

\author{
RICHARD F. HAFF \\ Smith Kline \& French Laboratories, 1500 Spring Garden Street, \\ Philadelphia, Pennsylvania 19101, USA
}

\begin{abstract}
Since viruses depend on cellular enzymes for their synthesis, they are less amenable than more complex organisms to selective inhibition. However, our knowledge of viral-specific intracellular events has increased and the feasibility of viral chemotherapy has become more firmly established at least in selected situations. For example, idoxuridine, methisazone, and amantadine represent three separate chemical classes of agents generally considered to be efficacious in the treatment of viral infections in man. The use of idoxuridine against herpes keratitis in man is well established; its clinical utility for dermal herpetic infections is less clear. Other unnatural nucleosides such as Ara-C and Ara-A also exhibit antiviral activity in various experimental infections. Methisazone has been used to prevent smallpox and alastrim in clinical contacts; it has also been used with apparent success in the treatment of vaccinia gangrenosa and eczema vaccinatum. Other thiosemicarbazones also possess similar intrinsic antiviral activity. Amantadine inhibits certain strains of influenza. Prophylaxis has been achieved in challenge studies and field trials against influenza A2. From more limited studies it also appears that this compound can be used therapeutically, that is, against already established infections. Other cyclic amines with activity against influenza are under study (e.g. rimantadine and cyclooctylamine). Relatively few additional chemical antiviral agents that hold promise for clinical utility are known at this time. However, there is considerable interest in the potential use of human interferon and interferon inducers. Human interferon is active in model infections, and it thas been reported to be efficacious against influenza in man. Currently, there are serious technical impediments to its economic production. These problems may be circumvented by the use of inducers, but as yet no compound with the required combination of properties has been found. A few preparations have demonstrated high potency in selected model infections, but they appear too toxic for parenteral use in man. The recent observation that an orally active low molecular weight compound (tilorone) possesses interferon inducing activity may pave the way for further advances in this area.

Past experiences in viral chemotherapy and an increasing knowledge of the mechanisms of viral infections should better enable us to chart a more productive future course. The processes of compound selection, choice of screening strategy, and market goals can now be better directed. Also, contrary to past predictions, the possibility of therapy as opposed to prophylaxis appears more likely. The present status of viral chemotherapy may be likened to that of the early sulphonamide era in bacteriology. Clinically active compounds are available and the probability of finding more effective agents is very high.
\end{abstract}




\section{INTRODUCTION}

A review of viral chemotherapy in a symposium devoted predominantly to antibacterials will illustrate the striking contrast between the progress achieved in these allied areas. This is no chance event. Whereas most microorganisms have evolved into separate entities having novel structural features and biochemical processes permitting independent existence, viruses are obligate intracellular parasites, largely dependent on the cellular enzymes of the host for their synthesis. Thus, far fewer opportunities are generally available for selective inhibition. Also, this intimate virus-host relationship has precluded development of comparably simple in vitro procedures for compound screening and evaluation.

Despite these considerations, the feasibility of viral chemotherapy has been firmly established. We are increasingly aware of viral-specific events and enzymes that are theoretically amenable to selective inhibition. From a more practical standpoint, there are now several drugs that have utility in treating viral infections in man. Other compounds have been shown to possess activity in different model infections, but for various reasons these have failed to materialize as products. Further advances will undoubtedly be made, but the potential for viral chemotherapy is shrouded in a controversy based, in no small measure, on projections from past experience, dogma, and a still rudimentary knowledge of the pathogenesis of viral disease.

I shall review the current status of viral chemotherapy, but perhaps more importantly, I shall attempt to clarify some of the basic issues pertinent to an appraisal of future progress in this area. The scope of this discussion will be limited to antiviral compounds, that is, those chemotherapeutic agents whose activity depends on an inhibition of viral replication. I will not attempt a comprehensive review, but instead emphasize topics of personal interest and data from our own laboratory. No consideration will be given to the pharmacological, or symptomatic, approach. Likewise, the control of viral disease by immunologic means is a separate topic. The prophylactic value of selected vaccines is well recognized, and the prophylactic use of immunoglobulins may also be beneficial in certain situations.

\section{ANTIVIRAL AGENTS OF CLINICAL INTEREST}

There are currently three classes of antiviral agents with at least one representative of each which is generally considered to be efficacious in man. These three classes are the unnatural nucleosides such as idoxuridine, the thiosemicarbazones, exemplified by methisazone, and the cyclic amines of which amantadine hydrochloride is the most widely studied.

\section{A. Unnatural nucleosides}

\section{Idoxuridine}

This halogenated deoxynucleoside is an analogue of thymidine (Figure 1). While it was originally studied in conjunction with cancer chemotherapy, its antiviral activity against herpes simplex was first demonstrated in vitro in an industrial screening programme in which a variety of antimetabolites were examined ${ }^{1}$. Its ability to inhibit other DNA viruses, including herpes zoster, is shown in Figure 2. In this test $50 \mu \mathrm{g}$ of the compound on a filter 


\section{PROBLEMS AND PROGRESS IN VIRAL CHEMOTHERAPY}

paper disc produces a zone where marked inhibition of plaque development is evident; an infected but untreated control plate is shown for comparison. Lower concentrations (to $0.5 \mu \mathrm{g}$ ) are also effective; zone size decreases in proportion to the amount added. Various DNA viruses are also inhibited

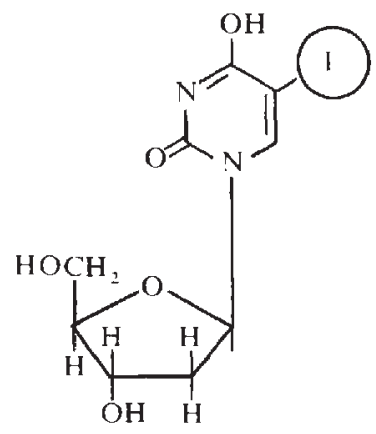

5-Iodo-2'-deoxyuridine

(Idoxuridine)

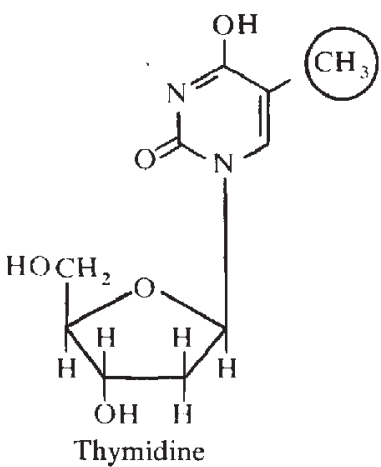

Figure 1.

by idoxuridine in model animal infections, for example, development of adeno 12 tumours in hamsters ${ }^{2}$, vaccinia ${ }^{3}$ and herpes keratitis ${ }^{4}$ in rabbits. and herpes dermatitis in both rabbits ${ }^{5}$ and guinea-pigs ${ }^{6}$. Two RNA viruses. Columbia SK and Rous sarcoma, are also sensitive to inhibition in mice and cell culture, respectively ${ }^{7.8}$; in these instances compound action may be indirect.

The observation of activity against herpes simplex in cell culture provided the impetus for Kaufman to test the compound topically in rabbits against

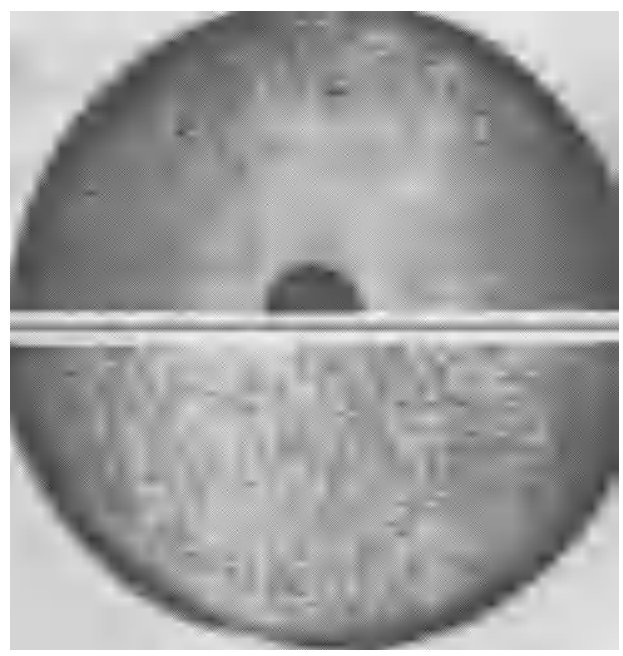

Figure 2. Plaque inhibition of herpes zoster by $50 \mu \mathrm{g}$ of idoxuridine. 


\section{RICHARD F. HAFF}

herpes keratitis ${ }^{4}$. Idoxuridine was clearly able to obliterate corneal disease promptly in a majority of animals. A pictorial record of such treatment is illustrated in Figure 3. Plate 1 shows the lesion two days after virus innoculation. A fluorescein-methylene blue solution was used for staining. Treatment
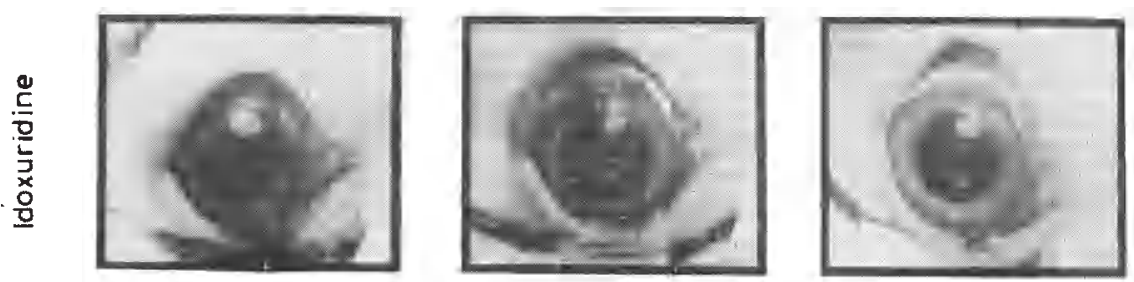

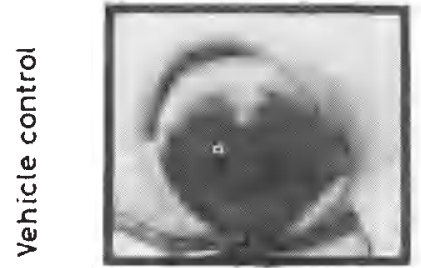

2 days

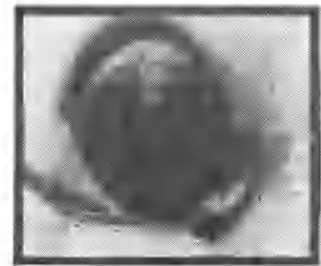

4 days

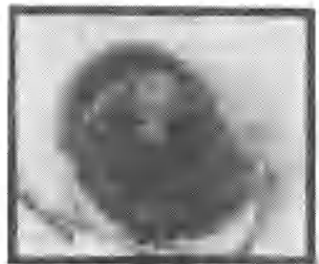

5 days

Post-infection

Figure 3. Eftect of idoxuridine ophthalmic solution (0.1 per cent) on herpes simplex lesions in the rabbit eye. Treatment six times daily beginning 48 hours post-infection.

was initiated at this time; one drop of a 0.1 per cent ophthalmic solution of idoxuridine was added six times daily over a 12-hour period on consecutive days. Plate 2 shows the results two days later. It is evident that the treated lesion is much smaller than the control. Following three days of treatment, the eye appears normal as shown in Plate 3. In control animals, lesions usually regressed gradually after 7-8 days, often with residual scarring.

In man, as in animals, Kaufman demonstrated that idoxuridine is an effective therapeutic agent for dendritic keratitis with or without superficial stromal lesions ${ }^{9}$. His conclusions are borne out in a compilation of data (Table 1) summarizing some early experience with Stoxil ${ }^{\mathbf{B}}$, a drug product containing idoxuridine. Out of 1760 cases, 1490 , or 85 per cent, responded favourably; the drug was equally effective against primary and recurrent disease. Stromal disease, on the other hand, was relatively refractory. Partial success has been achieved by combination therapy with Stoxil ${ }^{\mathbb{B}}$ and corticosteroids. Alone, steroid application frequently leads to extensive spread of the infection, but in the presence of idoxuridine the infection may be contained, so that the beneficial effects of the steroid on stromal healing can be obtained. Idoxuridine therapy is now well-established for the treatment of herpes keratitis, the most severe corneal infection in the United States and Europe. There are approximately 100000 cases per year in the US and they are responsible for the majority of corneal transplants that are required. 
PROBLEMS AND PROGRESS IN VIRAL CHEMOTHERAPY

Table 1. 0.1 per cent Idoxuridine therapy of herpes keratitis ${ }^{a}$

\begin{tabular}{|c|c|c|}
\hline Clinical disease & No. cases & $\begin{array}{l}\text { Good-excellent } \\
\text { response (per cent) }\end{array}$ \\
\hline \multicolumn{3}{|l|}{ Superficial } \\
\hline Primary & 949 & 85.5 \\
\hline Recurrent & 811 & 83.7 \\
\hline \multicolumn{3}{|l|}{ Deep } \\
\hline Primary & $72^{b}$ & $66.7^{b}$ \\
\hline Recurrent & $151^{b}$ & $72.1^{b}$ \\
\hline
\end{tabular}

a Data from J. A. Gold et al. ${ }^{10}$

b Concurrent steroid therapy

The success of treating herpes dermatitis with idoxuridine has been variable. Activity has been demonstrated in rabbits ${ }^{5}$ and guinea-pigs ${ }^{6}$ with systemic treatment. In addition, topical applications of a nine per cent solution of idoxuridine in 90 per cent dimethyl sulphoxide (DMSO) promoted healing of guinea-pig lesions ${ }^{5}$. Lower concentrations in other formulations failed to influence lesions in the rabbit ${ }^{11}$. Presumably, the greater concentration and better penetration achieved when DMSO was used as a solvent was decisive for activity. Clinical results appear to reflect the experience in animals. Data obtained in clinical impression studies using a 0.5 per cent dermatological ointment showed 63 per cent efficacy ${ }^{10}$. However, these results were not confirmed in double-blind studies. On the other hand, higher concentrations of idoxuridine in DMSO have provided clinical activity against both herpes dermatitis ${ }^{12,13}$ and herpes zoster ${ }^{14}$. The application of these findings to clinical practice remains questionable.

It was originally thought that the toxicity of idoxuridine precluded its systemic application. Although contraindicated for mild or self-limiting disease, an increasing compilation of data suggests its possible utility against herpes simplex encephalitis ${ }^{15}$. It is still an investigational drug when used for this purpose, and its use is indicated only in a diagnosed herpetic infection early after onset of the infection.

Considerable information is available on the action mechanism of idoxuridine. Its functions relate to its similarity to thymidine; the only difference between the two compounds being at the 5-position of the pyrimidine ring where iodine is substituted for a methyl group. A composite representation of mechanisms by which the compound may inhibit synthesis of viral or

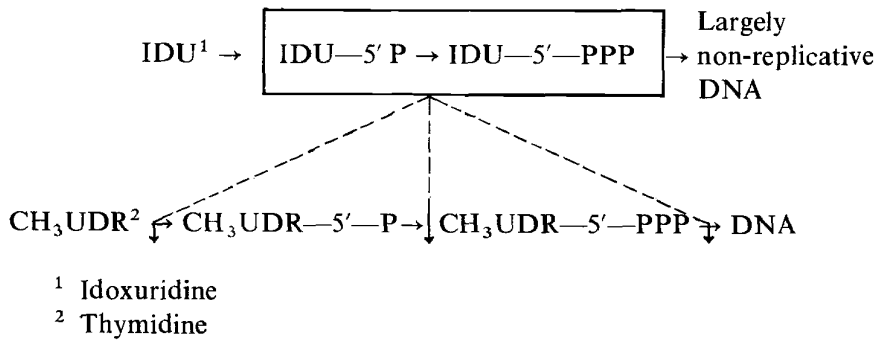

Figure 4. Action mechanism of idoxuridine. 
cellular DNA is shown in Figure 4. Following phosphorylation by thymidine kinase which enables it to enter the cell, idoxuridine competitively inhibits the utilization of thymidine. Several different sites of inhibition have been proposed. Idoxuridine may inhibit not only the kinases responsible for phosphorylation of thymidine and thymidylic acid, but also polymerases which catalyse the incorporation of thymidine triphosphate into DNA. In addition, idoxuridine is incorporated into DNA to some extent. The relative sensitivity of different enzymes to inhibition varies with the system ${ }^{16}$.

The apparent selective antiviral effect of idoxuridine probably has several explanations. Under conditions of maintenance in cell culture, it is obvious that viral synthesis may be blocked with little detrimental effect to the cells. Similarly, lack of corneal toxicity with idoxuridine therapy may result from the normal low rate of mitosis in this tissue. On the other hand, normal corneal repair in the presence of idoxuridine is difficult to explain on this basis. However, other mechanisms may be operative. For example, studies in cell culture show that herpes simplex infection induces thymidine kinase activity ${ }^{17}$. As a result, a greater amount of idoxuridine is taken up and incorporated into the DNA of infected cells than in normal tissue.

\section{Other unnatural nucleosides}

Other unnatural nucleosides have also shown activity against herpes keratitis. Cytosine arabinoside (Ara-C) is active both in rabbits and man ${ }^{18,19}$ but corneal toxicity contraindicates its clinical use ${ }^{20} .5$-Bromodeoxyuridine ${ }^{20}$, 5-methylaminodeoxyuridine ${ }^{21}$ and 5-trifluoromethyldeoxyuridine ${ }^{22}$ have exhibited similar activity in rabbits. None has been considered to have sufficient clinical advantage over idoxuridine to merit product development. Trifluoromethyldeoxyuridine is more potent but its synthesis is difficult. Ara-A (adenine arabinoside) is of more recent interest. Active in vitro against a broad spectrum of DNA viruses ${ }^{23,24}$, it has also been reported to have appreciable oral activity against herpes simplex encephalitis in hamsters ${ }^{25}$ and mice $^{26}$, and against mouse vaccinia encephalitis ${ }^{27}$. Its oral therapeutic index in hamsters is superior to idoxuridine ${ }^{25}$.

\section{B. Thiosemicarbazones}

\section{Methisazone}

The antiviral properties of a thiosemicarbazone ( $p$-amino benzaldehyde 3-thiosemicarbazone) were first demonstrated by Hamre in 1950 using a vaccinia infection in eggs and neurovaccinia in mice ${ }^{28}$. Many compounds in this chemical class possess such activity ${ }^{29,30}$. Methisazone (Figure 5), a later analogue, was shown by Bauer and Sadler in 1960 to be more effective ${ }^{30}$. Subsequently, a wide range of viruses were found to be sensitive in vitro ${ }^{31-33}$,

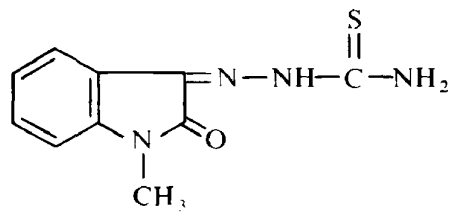

Figure 5. 1-Methylisatin-3-thiosemicarbazone (methisazone). 
PROBLEMS AND PROGRESS IN VIRAL CHEMOTHERAPY

but animal activity has been limited to the poxvirus group: alastrim ${ }^{34}$, rabbit pox ${ }^{35}$ and smallpox ${ }^{36}$. Remarkably good protection has been obtained in many instances as exemplified in Figure 6. In this instance the compound

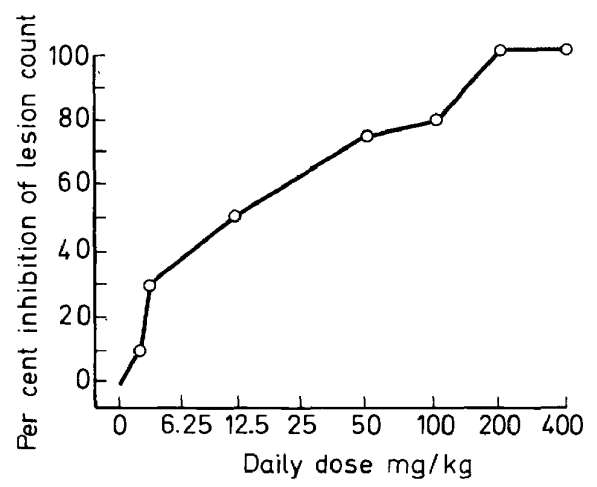

Figure 6. Effect of methisazone against vaccinia tail infection in mice.

was administered orally, once a day, commencing 24 hours after infecting mice with vaccinia. Tail lesions resulting from infection were significantly reduced in treated animals over a wide dose range.

In the clinic, Bauer and others have demonstrated efficacy with methisazone in the prophylaxis of smallpox by administering the compound to large numbers of contacts ${ }^{37,38}$. A similar prophylactic trial against alastrim provided similar indications of activity ${ }^{39}$. A compilation of these data is presented in Table 2. The compound was effective in smallpox contacts

Table 2. Prophylaxis of smallpox and alastrim with methisazone.

\begin{tabular}{|c|c|c|c|c|}
\hline Disease contact & No. contacts & Treatment & No. cases & No. deaths \\
\hline Smallpox $^{a}$ & $\begin{array}{l}2297 \\
2842\end{array}$ & $\begin{array}{l}\text { Yes } \\
\text { No }\end{array}$ & $\begin{array}{r}6 \\
114\end{array}$ & $\begin{array}{r}2 \\
20\end{array}$ \\
\hline Alastrim $^{b}$ & $\begin{array}{l}384 \\
520\end{array}$ & $\begin{array}{l}\text { Yes } \\
\text { No }\end{array}$ & $\begin{array}{r}8 \\
42\end{array}$ & $\begin{array}{l}0 \\
0\end{array}$ \\
\hline
\end{tabular}

a Data from D. J. Bauer ${ }^{38}$

${ }^{b}$ Data from L. A. Ribeiro Do Valle et al. ${ }^{39}$

regardless of their vaccination status. Different amounts and dosage regimens of the compound were employed, but relatively large oral doses of methisazone have been preferred (e.g. a total dose up to $24 \mathrm{~g}^{38}$ ). Vomiting has been observed in a high proportion of patients. Administration of methisazone may be advisable in selected situations where rapid prophylaxis is required, but certainly mass vaccination is a more reasonable measure for smallpox and alastrim control.

No therapeutic activity against smallpox has been demonstrated, although few trials have been reported. On the other hand, therapeutic activity has been reported for eczema vaccinatum and vaccinia gangrenosa ${ }^{38,40-45}$. 
RICHARD F. HAFF

Table 3. Clinical impressions of methisazone therapy $\dagger$

\begin{tabular}{lcc}
\hline \multicolumn{1}{c}{ Disease } & No. patients & Per cent benefit \\
\hline $\begin{array}{l}\text { Eczema } \\
\text { vaccinatum }\end{array}$ & 33 & 70 \\
$\begin{array}{l}\text { Vaccinia } \\
\text { gangrenosa }\end{array}$ & 21 & 57 \\
\hline
\end{tabular}

$\dagger$ Data from B. R. Adels et al. ${ }^{40}$, A. J. E. Barlow ${ }^{41}$, D. J. Bauer ${ }^{38}$, B. JaroszynskaWeinberger ${ }^{42}$, C. H. Kempe ${ }^{43}$, D. Mainwaring ${ }^{44}$ and W. Turner et al. ${ }^{45}$

These data are summarized in Table 3. Since eczema vaccinatum, particularly, runs a variable course and the numbers of patients in the studies are small, the suggested benefit of treatment must be viewed with caution, but is promising nonetheless.

Action mechanism studies have been largely restricted to the effect of isatin-3-thiosemicarbazone (IBT) on vaccinia or rabbitpox. IBT inhibits neither vaccinia DNA nor mRNA synthesis ${ }^{46,47}$. Protein synthesis is selectively blocked, but only after progeny genomes appear ${ }^{48,+9}$. It is inferred that the function of mRNA required for synthesis of late proteins which package the DNA core is affected. Replication of rabbitpox DNA is similarly unaffected whereas selected viral antigens formed late in the growth cycle fail to appear ${ }^{50}$. Thus, a similar inhibitory mechanism is indicated. Presumably methisazone has a similar effect against pox viruses but whether unrelated viruses, i.e. rhinoviruses ${ }^{31}$, are sensitive for the same reason is unknown.

\section{Other thiosemicarbazones}

In addition to methisazone, a number of other close analogues were found active against neurovaccinia in mice ${ }^{29,30}$. None has been tested in man. Although the $N$-ethyl analogue was somewhat more active in mice than methisazone, the latter was selected for clinical use due to greater ease of synthesis.

A more distantly related thiosemicarbazone, designated as May and Baker 7714 (Figure 7) and also effective against pox viruses in animals, has<smiles>Cc1nsc(/C=N/NC(N)=S)c1Br</smiles>

Figure 7. 4-Bromo-3-methylisothiazole-5-carboxaldehyde thiosemicarbazone(M \& B 7714).

been evaluated in man against smallpox in a manner similar to that of methisazone ${ }^{51}$. Protection was observed, but to a lesser degree than with methisazone. The incidence of smallpox was 33 per cent in a control group of 147 persons whereas in a treated group of the same size, the incidence was 18 per cent. A similar proportion of deaths among smallpox patients was observed in each group. In a later therapeutic study there was no evidence of 
activity $^{52}$. Again, this drug was not well-tolerated, with vomiting the major side effect.

\section{Cyclic amines}

1. Amantadine

Amantadine (Figure 8) is an analogue of octachloroadamantane synthesized as a result of in vitro activity observed with the parent compound against influenza in an industrial screen. With two exceptions (pseudorabies ${ }^{53,54}$

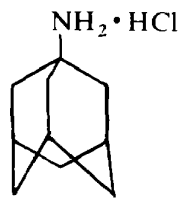

Figure 8.1 -Adamantanamine hydrochloride (amantadine hycirochloride).

and vaccinia ${ }^{55}$ ) the in vitro antiviral activity of amantadine (Table 4) is confined to RNA 'membrane' viruses (i.e. influenza A, A1, A2 and $\mathrm{C}^{54}$, parainfluenza/ $1^{54}$ and $3^{55}$, fowl plague ${ }^{56}$, rubella ${ }^{57}$, transmissible gastroenteritis $^{58}$ and Rous sarcoma ${ }^{59}$. Related viruses (influenza B, other parainfluenza strains, Newcastle disease and mumps) and many others are not inhibited ${ }^{54}$. Studies in eggs support the observed activity in vitro against influenza A strains ${ }^{54}$. Amantadine also reduces mortality and increases

Table 4. In vitro activity of amantadine hydrochloride.

Fowl plague
Influenza A
Influenza A1
Influenza A2
Influenza C
Parainfluenza 1
Parainfluenza 3
Pseudorabies
Rous sarcoma
Rubella
Transmissible gastroenteritis
Vaccinia

survival time of mice infected with influenza $A$ viruses ${ }^{60}$. The difference in sensitivity among influenza A strains in this system may be considerable as illustrated in Figure 9. Influenza A/PR8 is essentially refractory, but A2/Ann Arbor is significantly inhibited. The reason for these differences is not known. Amantadine also provides activity against influenza A viruses in the horse ${ }^{61}$; no activity was observed in ferrets but influenza A/PR8 was used as the virus inoculum in this study ${ }^{62}$.

A number of prophylactic studies with amantadine have now been carried out in humans against influenza A2 either in challenge situations ${ }^{63-67}$ or in 
natural settings ${ }^{68-74}$. With the exception of one challenge study ${ }^{65}$ amantadine apparently reduced the incidence and/or severity of infection as judged by laboratory and/or clinical criteria. The utility of amantadine for prophylaxis of influenza was questioned ${ }^{75}$ on the basis of data generated in the initial series of studies, principally because there was insufficient demonstration of clinical effect in the field. Later investigations, using 4559 treated subjects in Leningrad during an influenza A2/Hong Kong epidemic in 1969, reinforced the initial contention that the compound was active. In this study

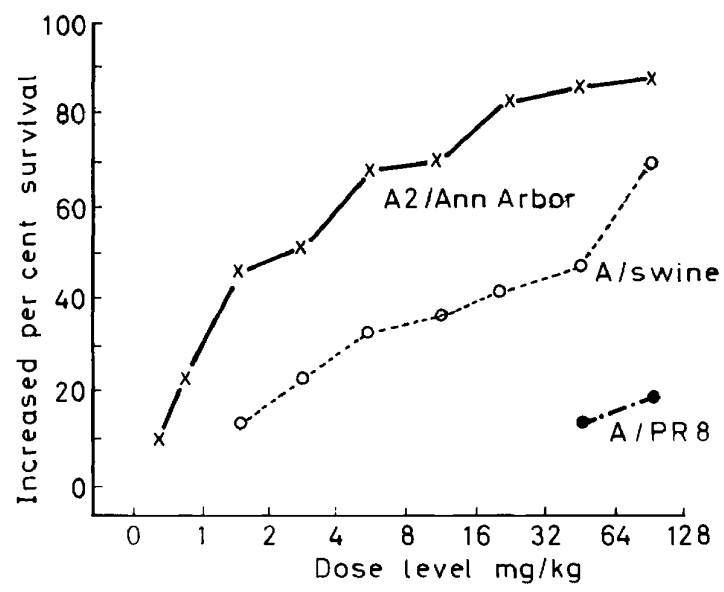

Figure 9. Amantadine hydrochloride vs. $\mathrm{LD}_{90}$ infection of mice with different influenza A viruses (multiple oral $\mathrm{Rx}$ from $3 \mathrm{~h}$ pre-infection).

influenza-associated illness was reduced approximately 50 per cent and the severity of illness when it occurred was lessened ${ }^{72}$. No effect was obtained against rubella ${ }^{76}$, another virus sensitive in vitro, nor against influenza $\mathbf{B}^{67}$ (an in vitro insensitive virus). At the recommended adult oral dose of $200 \mathrm{mg}$ per day mild manifestations of central nervous system effects such as nervousness, insomnia and psychic reactions have been observed, but only in small numbers of patients ${ }^{77}$. Side effects of this type increase in severity and incidence with dosage ${ }^{78}$.

Several recent studies conclude that amantadine possesses limited therapeutic activity against influenza $A 2^{73,79-81}$. The results of these studies are summarized in Table 5. All studies suggest benefit from grug treatment. Virus isolates varied but in most studies were A2/Hong Kong serotypes. In most instances the drug was first administered during the initial 48 hour period of fever, but data on some patients with a longer duration of fever are also included. Generally a significant reduction in duration of fever was obtained, particularly in those patients who were treated early. Also, subjective clinical signs and symptoms were reduced in duration and/or severity. Quantitative values to express these effects were generally not amenable to this type of tabulation. If the results of these studies are substantiated by 


\section{PROBLEMS AND PROGRESS IN VIRAL CHEMOTHERAPY}

Table 5. Summary of therapeutic studies with amantadine hydrochloride in human volunteers naturally infected with influenza $\mathrm{A} 2$ strains.

\begin{tabular}{|c|c|c|c|c|}
\hline \multirow{2}{*}{$\begin{array}{l}\text { Study } \\
\text { and } \\
\text { year }\end{array}$} & \multirow{2}{*}{$\begin{array}{l}\text { No. volunteers } \\
\text { drug/placebo }\end{array}$} & \multirow{2}{*}{$\begin{array}{l}\text { Reduction in } \\
\text { duration of } \\
\text { fevet }(h)\end{array}$} & \multicolumn{2}{|c|}{ Reduction in illness } \\
\hline & & & Duration (h) & Severity \\
\hline $\begin{array}{l}\text { Floor-Wieringa } \\
\text { et al. }{ }^{73} \\
(1965-1966)\end{array}$ & $37 / 34$ & $(p=0.09)$ & $\begin{array}{c}72 \\
(p<0.05)\end{array}$ & Not reported \\
\hline $\begin{array}{l}\text { Wingfield et al. }{ }^{80} \\
(1968)\end{array}$ & $20 / 39$ & $\begin{array}{c}22 \\
(p<0.05)\end{array}$ & $\begin{array}{c}14 \text { to } \\
50 \% \text { improvement } \\
(p<0.05)\end{array}$ & $\begin{array}{c}\text { Yes } \\
(p<0.05)\end{array}$ \\
\hline $\begin{array}{l}\text { Togo et al. }{ }^{79} \\
(1967-1968)\end{array}$ & $54 / 48$ & $\begin{aligned} & \sim 27 \\
(p<0.05) & \end{aligned}$ & $\begin{array}{c}\text { Yes } \\
(p<0.05)\end{array}$ & $\begin{array}{c}\text { Yes } \\
(p<0.05)\end{array}$ \\
\hline $\begin{array}{l}\text { Knight et al. }{ }^{81} \\
\text { (1969) }\end{array}$ & $13 / 16$ & $\begin{array}{c}27 \\
(p<0.05)\end{array}$ & Not reported & $\begin{array}{l}\text { Positive trend } \\
\quad(p>0.05)\end{array}$ \\
\hline
\end{tabular}

much further investigation, the use of amantadine against flu-like illness may be merited during epidemics of influenza A2.

Immunization is still the first line of defence against influenza. Nonetheless, amantadine may be a useful adjunct, particularly in high-risk groups, during proven influenza A2 epidemics. Whether succeeding strains of influenza will share the in vivo sensitivity of $\mathrm{A} 2$ viruses or be refractory, as is A/PR8, can only be speculated.

Action mechanism studies with influenza A strains reveal that amantadine inhibits the penetration of the virus into the cell ${ }^{82}$. Other studies employing fowl plague virus show that the virion penetrates the cell, but that the subsequent uncoating of viral nucleic acid is inhibited ${ }^{56}$. Since the nature of the penetration step with influenza is not known, the two results may be compatible.

\section{Other cyclic amines}

Approximately 50 additional mono-, bi- and tri-cyclic amines of varying structure have been found active against influenza A2 mouse infections in our laborator ${ }^{83}$. One of the simpler, more active, and best tolerated of these is cyclooctylamine (Figure 10$)^{84}$. Oral dosing of mice provides activity comparable to that of amantadine. In addition, intranasal administration is

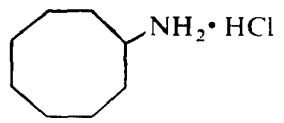

Figure 10. Cyclooctylamine hydrochloride.

highly effective as shown by exposing mice infected with influenza A2 to aerosols of the compound at multiple times over a three day period (Figure 11). The compound is similarly effective when administered by drop instillation. 


\section{RICHARD F. HAFF}

In addition, cyclooctylamine can inhibit natural spread of influenza among ferrets ${ }^{85}$. This compound is currently under clinical evaluation in man.

Still other cyclic amines have been reported to have antiviral activity. For

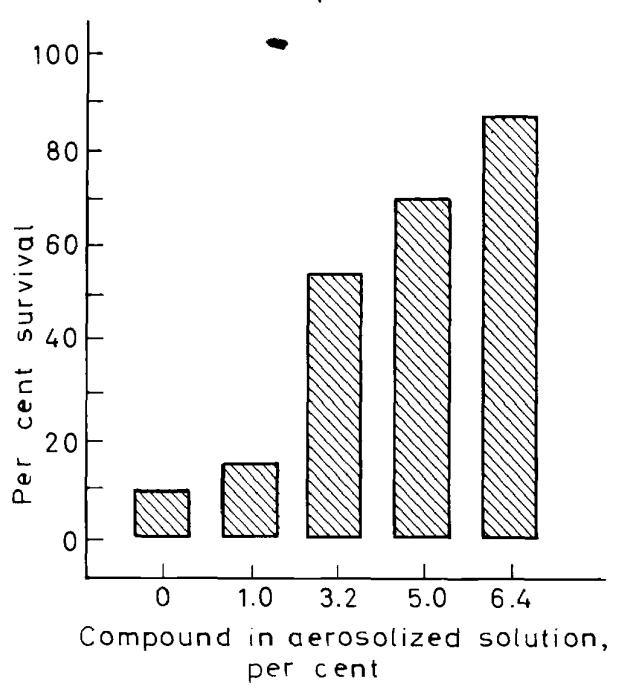

Figure 11. Effect of aerosolized cyclooctylamine hydrochloride on survival of mice infected with influenza A2.

example, $N$-methyl-adamantane-2-spiro-3'-pyrrolidine has been studied extensively in the laboratory and is considered to have a slightly better therapeutic index than the parent compound ${ }^{86}$. Rimantadine hydrochloride (Figure 12) has also shown good in vitro and in vivo activity against infection

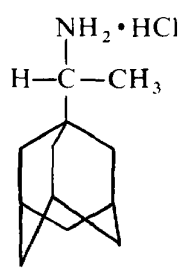

Figure 12. $\alpha$-Methyl-1-adamantane methylamine hydrochloride (rimantadine hydrochloride).

by influenza $A$ viruses ${ }^{87,88}$. In human volunteers, a prophylactic effect equivalent to that of amantadine was observed in one challenge study ${ }^{89}$ and therapeutic value, again comparable to that of amantadine, has been indicated in two studies with natural infection ${ }^{80,90}$.

\section{INTERFERON AND INTERFERON INDUCERS}

A review of viral chemotherapy would be incomplete without considering 
the potential clinical use of exogenous interferon or interferon inducers. Although interferon was described in $1957^{91}$ and, in retrospect noninfectious interferon inducers were available since the discovery of statalon ${ }^{92}$ in 1952 and helenine ${ }^{93}$ in 1953, few clinical studies with such materials have been reported to date. A large volume of laboratory data has appeared, however, which reflects the great interest in this area, and has been the subject of recent comprehensive reviews ${ }^{94,95}$.

Interferons are low molecular weight proteins synthesized by cells in response to viral and other microbial infections, as well as to certain viral nucleic acids and non-viral substances. Their in vitro activity extends to virtually all viruses, but has considerable quantitative differences in sensitivity. In animal infections their antiviral spectrum is more limited, presumably because of differences in viral sensitivity and disease pathogenesis, but the range of antiviral protection, particularly with inducers, is impressive. In addition, interferons are essentially non-toxic and non-antigenic in the homologous host. Consequently, they are of great practical interest.

Impediments to the use of exogenous interferon relate primarily to production. In addition, interferons are not orally active and human interferon has been considered unstable when concentrated. Since interferons are, to a large extent, species specific, interferon for human use must be obtained from either monkey or human cells. Cultured cells vary widely in their capacity to produce this material by present methods of manipulation. Production in human leukocytes (buffy coats obtained from blood banks) is currently the most practical method ${ }^{96,97}$. Even here, yields are low and new technology is needed before interferon can be produced economically for wide usage.

Limited studies indicate that human interferon is efficacious in sub-human primates. Used intravenously, it has been effective against vaccinia ${ }^{98}$ in baboons, and vaccinia ${ }^{99}$ and yellow fever ${ }^{100}$ in monkeys. It is also effective intradermally against monkey vaccinia dermatitis ${ }^{100}$. The following study illustrates the effects that can be obtained (Table 6). Vaccinia was titrated intradermally on the backs of rhesus monkeys. Human leukocyte interferon was injected intravenously at different doses by the indicated regimens. A

Table 6. Inhibition of vaccinia dermatitis in rhesus monkeys by human leukocyte interferon.

\begin{tabular}{|c|c|c|c|c|c|}
\hline \multirow{2}{*}{ Treatment } & \multirow{2}{*}{$\begin{array}{l}\text { IV. dose } \\
\text { units } \dagger / \mathrm{kg}\end{array}$} & \multicolumn{3}{|c|}{ Treatment regimen $(h)$} & \multirow{2}{*}{$\begin{array}{c}\log _{10} \text { virus } \\
\text { titre } \\
\text { (Day } 6)\end{array}$} \\
\hline & & -24 & 0 & +24 & \\
\hline & 80000 & + & + & + & 2.17 \\
\hline Human & 80000 & + & + & - & 2.50 \\
\hline leukocyte & 80000 & + & - & - & 3.00 \\
\hline \multirow{3}{*}{ interferon } & 80000 & - & - & + & 3.00 \\
\hline & 800 & + & + & + & 2.00 \\
\hline & 8 & + & + & + & 3.50 \\
\hline $\begin{array}{l}\text { Interferon } \\
\text { negative } \\
\text { control }\end{array}$ & {[} & + & + & + & 3.50 \\
\hline
\end{tabular}

† IF dilution providing 50 per cent inhibition of VSV CPE in human foreskin fibroblasts. 
prophylactic effect was observed as indicated by a reduction in lesion titre, but there was only questionable activity when interferon was given first 24 hours after infection. The size of the remaining lesions in the prophylactic trial was also reduced as shown in Figure 13.

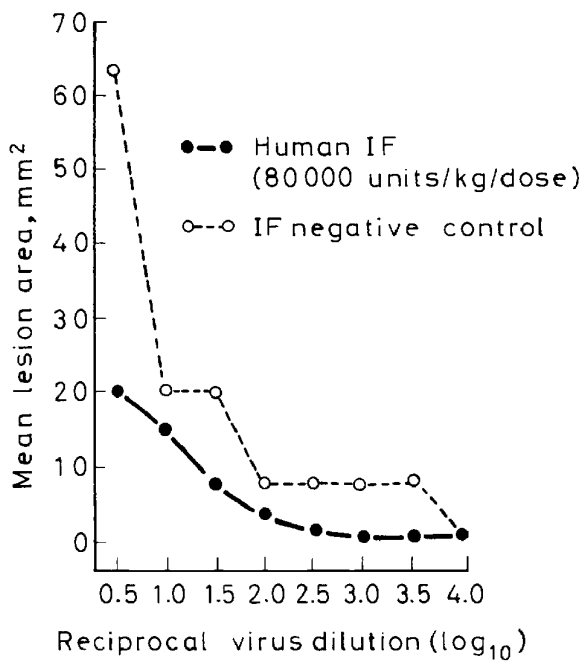

Figure 13. Dermal lesions in monkeys six days after vaccinia infection.

In man, monkey interferon has been reported to prevent the vaccination response when injected at the vaccination site ${ }^{101}$, and to be effective against vaccinia keratitis ${ }^{102}$ when administered topically. Of greater interest, human leukocyte interferon has been reported to lower the incidence of influenza A2-associated illness when applied intranasally during two natural disease outbreaks ${ }^{103,104}$. One of these studies, performed by Solov'ev, involved 5374 treated volunteers; approximately 60 per cent less disease was observed in this group than in a similar group of controls. In neither study was influenza confirmed by laboratory diagnosis. More important, there was no indication that controls were given a comparable preparation lacking interferon or that the interferon was examined for its level of influenza antibodies and nonspecific viral inhibitors. The latter are commonly present in high titres in interferon concentrates, since human serum is usually used in the leukocyte incubation medium. The intranasal administration of gamma-globulin (i.e. antibodies) has been shown to be similarly effective for the prophylaxis of an upper respiratory tract viral infection ${ }^{105}$. Therefore, beneficial results when obtained cannot be clearly attributed to the interferon content of the material. Other interferon trials ${ }^{96,106}$ in man have been limited in scope and tentative in conclusions. Further well-controlled studies are required to evaluate this chemotherapeutic approach.

An alternate and, possibly, more attractive approach to interferon therapy is the use of non-infectious agents which induce the body to synthesize its own interferon. A number of such substances are now known (Table 7). 
Table 7. Non-infectious interferon inducers with antiviral activity in vivo.

\begin{tabular}{|c|c|}
\hline Natural products & Synthetic polymers \\
\hline Alginic acid & Pyran copolymer \\
\hline Chlorite oxidized amylose & Polyacrylic acid \\
\hline Bacterial endotoxins & Polyvinyl sulphate. \\
\hline Fungal carbohydrate & Double-stranded RNA: \\
\hline Fungal single-stranded RNA & Poly I:Poly C \\
\hline \multicolumn{2}{|l|}{ Phy tohaemagglutinin } \\
\hline \multicolumn{2}{|l|}{ Mycophage } \\
\hline \multicolumn{2}{|l|}{ Double-stranded RNA from: } \\
\hline Mycophage & Simple synthetics \\
\hline Mushrooms & Tilorone hydrochloride \\
\hline Phage-infected bacteria & \\
\hline Plant viruses & \\
\hline DNA-RNA phage hybrid & \\
\hline
\end{tabular}

These materials are all high molecular weight polyanions with the exception of tilorone ${ }^{107}$. Statalon ${ }^{92}$ and helenine ${ }^{93}$, extracts from Penicillium stoloniferum and $P$. funiculosum, respectively, were the first described. The activity of these materials is now known to be associated with mycophage ${ }^{108,109}$, which on further extraction provided double-stranded RNA having high antiviral potency ${ }^{110,111}$. Largely on the basis of these findings, other double-standard RNAs were examined. Virtually all from natural sources have been active in vivo. They have been obtained from other fungal species such as Penicillium ${ }^{12,113}$, Aspergillus ${ }^{114}$ and a mushroom ${ }^{15} ;$ E. coli infected with MS2 ${ }^{116}$ and MU9 ${ }^{117}$ phage; and certain plant viruses ${ }^{117}$. A complex of biosynthetic RNA homopolymers is similarly active, polyinosinic and polycytidylic acid (Poly $\mathrm{I}: \mathrm{C})^{118}$. Double-strandedness is frequently considered to be a requirement for in vivo activity presumably due, at least in part, to rapid enzymatic hydrolysis of the RNA homopolymers. A singlestranded RNA from the fungus Cunninghamella blakesleeana has been shown active ${ }^{119}$, however, reflecting activities occasionally obtained in vitro with high concentrations of homopolymers ${ }^{120,121}$. Possibly its base sequence or tertiary structure is unusally resistant to nucleases. Similar considerations may explain the in vivo activity of a DNA-RNA F1 phage hybrid ${ }^{117}$.

Other polyanions were found active concurrent with work in the RNA area. These include several carbohydrates (chlorite oxidized amylose ${ }^{122}$ and a polysaccharide from $C$. blakesleean $a^{119}$ ); some more complex natural products such as alginic acid ${ }^{12}$, phytohaemagglutinin ${ }^{123}$ and bacterial endotoxins $^{124}$; and several plastics (pyran copolymer ${ }^{123}$, polyacrylic acid ${ }^{125}$ and polyvinyl sulphate ${ }^{126}$ ).

Many other such compounds have been shown to induce interferon either in vitro or in vivo, and to provide in vitro antiviral protection, but their ability to protect animals against infection either has not been examined or reported. The conclusion that the observed in vivo activity is a consequence of interferon induction is somewhat tenuous. Circulating interferon is frequently not demonstrable at protective doses, or protection may extend far beyond the time that interferon levels are observed. However, the association between 


\section{RICHARD F. HAFF}

these two events is borne out by several indirect lines of evidence. Since small quantities of interferon can produce antiviral activity, it is reasoned that levels present and persisting in target tissues are too low to be detectable by present assay methods. The antiviral potency of an interferon inducer against comparable infections in different hosts correlated directly with its ability

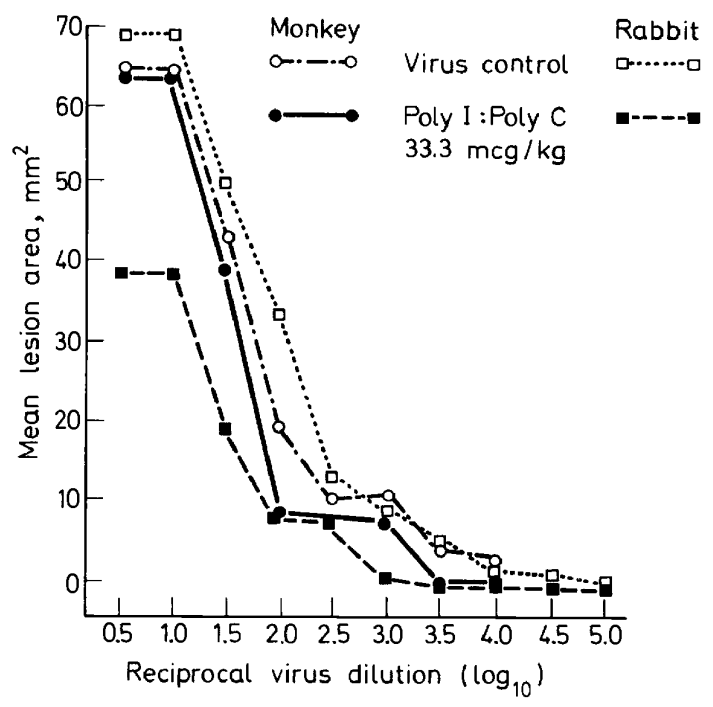

Figure 14. The effect of Poly I : Poly C on vaccinia dermal lesions six days after infection.

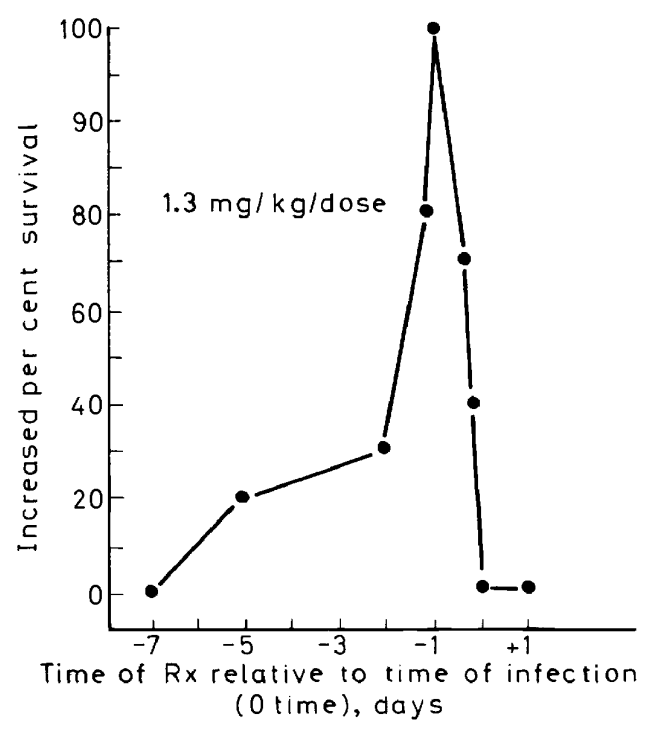

Figure 15. Effect of Poly I : Poly C on survival of mice infected with mengovirus. 
to induce interferon in these species ${ }^{127}$. Poly (I:C) induces high titres of interferon in the rabbit following intravenous administration of $2 \mu \mathrm{g}$ per animal $^{118}$, but none could be detected in the rhesus monkey after similar administration of $3 \mathrm{mg}$ per animal ${ }^{127}$. Protection studies with Poly (i:C) against vaccinia dermatitis in rabbits and rhesus monkeys are illustrated in Figure 14. The compound was administered intravenously 24 hours before infection. Although activity was demonstrable in both species, potency in the rabbit is significantly greater. Also, the inducers have a broad spectrum of antiviral activity reminiscent of interferon, provide a degree of protection in vivo which at least roughly correlates with the sensitivity of the virus to interferon in vitro, and exhibit a time lag to optimal effect; this is consistent with the fact that interferon is not detected in high titre in cultured cells for several hours after incubation with inducer, and antiviral activity is not optimally established until after that time. The relationship between time of Poly (I:C) administration and activity is illustrated for a mengovirus infection in mice in Figure $15^{83}$. The compound was administered intraperitoneally in a single dose of $1.3 \mathrm{mg} / \mathrm{kg}$ against an $\mathrm{LD}_{90}$ infection. Optimal activity was obtained when the compound was given 18 hours before infection, but activity diminished gradually with earlier dosing and rapidly, approaching the time of infection. Repeated dosing can sustain an antiviral effect. Duration of protection varies widely with the inducer. For example, polyacrylic acid can provide activity for at least eight weeks after administration ${ }^{125}$. Also, activity can be achieved against certain infections when inducers are administered after the time of virus inoculation. For example, Poly (I:C) provides significant protection against Semliki Forest ${ }^{128}$ and vaccinia ${ }^{129}$ viruses in mice when administered as late as five days after infection.

The in vivo profile of these inducers varies widely with respect to potency, therapeutic index, and extent of testing. The plastics have a relatively low order of activity. Serious side effects including fever and haematologic

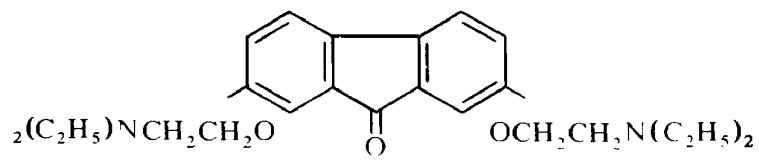

Figure 16. 2,7-Bis(2-(diethylamino)ethoxy) fluoren-9-one hydrochloride (tilorone hydrochloride).

disorders limit the use of pyran copolymer at effective levels in $\operatorname{man}^{130}$. Poly (I:C) likewise produces a spectrum of toxic effects in several species following parenteral administration at low doses ${ }^{131}$. It appears, however, that a favourable activity: toxicity ratio may be attainable by intranasal administration in man against selected viruses producing respiratory disease ${ }^{\mathbf{1 3 1}}$. Other inducers, notably carbohydrates and double-stranded RNAs from natural sources, have not been adequately evaluated in this respect.

Aside from questions of toxicity the use of the polymeric inducers is limited by their lack of oral activity: parenteral administration is indicated for 
systemic disease, and intranasal, for respiratory tract infections. Therefore, tilorone hydrochloride, which is active orally, parenterally and intranasally against a variety of laboratory infections, has attracted recent attention (Figure 16). This compound has a simple structure and represents a new class of interferon inducers. It is the only small molecular weight inducer and the only one of known structure. Unfortunately, potency is low and it remains for other compounds of this nature to be discovered.

Reported clinical studies have been limited to the use of Poly (I:C) ${ }^{132}$. In very small numbers of volunteers, intranasal administration of the compound provided suggestive evidence of protection against a rhinovirus and an influenza A2 challenge. However, no conclusions can yet be drawn on its clinical efficacy.

\section{OTHER ANTIVIRAL COMPOUNDS}

A vast assortment of additional compounds have been reported to have in vitro antiviral activity. Some of these have proven to be useful in the study of biosynthetic pathways, but most are of no practical interest. Far fewer, but still substantial numbers, have convincing activity in animal infections. For the most part their clinical efficacy is either not reported, or inadequately evaluated. However, several isoquinolines with laboratory activity against

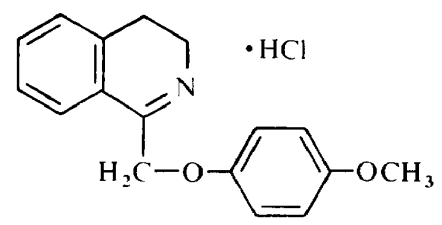

1(4-Methoxyphenoxy-methyl)-3,4-dihydroisoquinoline hydrochloride (UK 2371)

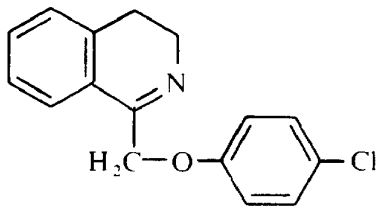

1(4-Chlorophenoxy-methyl)-3,4-dihydroisoquinoline hydrochloride (UK 2054)

Figure 17.

influenza ${ }^{133}$, have also been reported active against influenza A2 and B1 infections in limited human challenge studies (Figure 17) ${ }^{134-137}$. Data obtained with UK 2371 are variable, however, and provide little encouragement for more extensive evaluation with this particular derivative. ABOB is another antiviral whose clinical activity is not completely resolved (Figure 18). In a series of large field trials in Sweden carried out in the early 1960 s 


\section{PROBLEMS AND PROGRESS IN VIRAL CHEMOTHERAPY}

and reviewed by Dahlgren et al. ${ }^{138}$ the compound was considered to suppress symptoms and seroconversion to influenza A significantly. Other studies reported activity against adenovirus infections ${ }^{139,140}$. In contrast, studies in the US suggested no effect against an influenza A challenge ${ }^{141}$ and in a

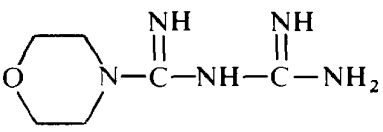

Figure 18. $N^{\prime}-N^{\prime}$-Anhydro-bis-( $\left(\beta\right.$ hydroxyethyl) biguanide (ABOB; Flumidin ${ }^{\mathrm{R}}$ )

field trial against influenza $\mathrm{A} 2$ and adenovirus infection ${ }^{142}$. The conflicting experiences and lack of profound activity in positive studies have negated wide interest in this compound.

\section{ISSUES PERTINENT TO FUTURE PROGRESS}

Through a great deal of effort, it has been shown that viral chemotherapy is feasible. The experience gained in this endeavour should better enable us to chart a future course and predict the outcome.

\section{A. Screening strategy}

The activity of all three clinically useful antiviral classes of compounds was first discovered by a more or less random screening process. However, the compound in question, or its prototype, had other known biological activity; thiosemicarbazones as antituberculars, octachloroadamantane as an insecticide, and idoxuridine per se as a recognized metabolic inhibitor. Random screening yields relatively few compounds of interest (Table 8). In a sampling of 4686 compounds screened in vitro in this laboratory, 8 per cent showed activity. Far fewer merited special attention. A better approximation of incidence of leads is provided by in vivo activity. Buthala relates that of 4320 compounds tested in vivo 0.33 per cent were active ${ }^{143}$. Having

Table 8. In vitro screening experience.

\begin{tabular}{lrcc}
\hline \multirow{2}{*}{ Virus } & \multicolumn{3}{c}{ Plaque inhibition screen } \\
\cline { 2 - 4 } & No. of tests & No. active & Per cent active \\
\hline Coxsackie B-1 & 661 & 16 & 2 \\
Herpes simplex & 504 & 134 & 27 \\
Influenza A, WSN & 1205 & 144 & 12 \\
Influenza A-2, JPT & 32 & 8 & 25 \\
Parainfluenza 1 & 374 & 22 & 0 \\
Parainfluenza 3 & 86 & 0 & 0 \\
Respir. syncytial & 704 & 0 & 5 \\
Rhino 1059 & 550 & 26 & 0.4 \\
Herpes zoster & 519 & 17 & 33 \\
Vaccinia & 51 & 369 & 8 \\
Total & 4686 & &
\end{tabular}




\section{RICHARD F. HAFF}

obtained a lead, the incidence of activity among analogues synthesized around this structure may be much greater. For example, 133 cyclic amines of varying structure were synthesized in this laboratory as a consequence of interest in cyclooctylamine. Fifty or 38 per cent were active in mice against influenza A2. The number of other active thiosemicarbazone analogues and substituted nucleosides appearing after the initial lead was obtained, attest to the success of similar analoguing programmes. Thus, it would appear that high volume random screening, the testing of all available compounds with known biological activity, and vigorous analoguing programmes around leads may provide additional payoff. Most antivirals of special interest today are synthetic. Many from a variety of natural sources, however, show in vitro activity, and several are active in animals. Problems in production, fractionation, and purification of such materials impede their evaluation but, as with antibacterials, natural products may ultimately be a rich source of antivirals.

\section{B. Screening methods}

The basic choices in screening methodology are between in vitro or in vivo models, and the selection of viruses. Compounds can be tested more efficiently against a greater variety of viruses in vitro. Possibly the plaque inhibition test is the system of choice. On the other hand, interest depends largely on activity in vivo, so that if 'appropriate' and easily manipulated small animal infections are available, they are often preferable for testing compounds directly. By so doing, certain antivirals deserving special attention may be missed but others, metabolized to active products or possessing indirect action, may be discovered. All screens have holes. Commonly used animal infections are often markedly dissimilar to the human target infections for

Table 9 . Spectrum of picornavirus activity in vitro with compounds active against $4 / 4$ rhinoviruses.

\begin{tabular}{cccccc}
\hline \multirow{2}{*}{ Compound } & \multicolumn{5}{c}{ In vitro spectrum } \\
\cline { 2 - 6 } & Eq. rhino & Cox. B1 & Cox. B3 & Polio 2 & Mengo \\
\hline 1 & + & + & + & + & + \\
2 & 0 & + & + & + & + \\
3 & 0 & 0 & 0 & 0 & ND \\
4 & 0 & 0 & 0 & + & ND \\
5 & + & 0 & 0 & 0 & ND \\
6 & 0 & + & + & + & 0 \\
7 & + & 0 & + & 0 & ND \\
8 & + & 0 & 0 & + & ND \\
\hline
\end{tabular}

which they are supposedly models. Lethal mouse infections are frequently used for convenience, yet most human viral infections are mild and selflimiting (i.e. influenza and herpes simplex). Their pathogenesis may also differ. Encephalitic infections are often used (i.e. herpes simplex and vaccinia) as models for predominantly non-encephalitic human diseases. Such a choice is hazardous, since many, particularly ionized compounds, fail to cross the blood-brain barrier. In general, an attempt is made to select viral strains which are closely related to those responsible for the target infections in man. 


\section{PROBLEMS AND PROGRESS IN VIRAL CHEMOTHERAPY}

This is readily accomplished in some instances (i.e. influenza, herpes simplex and vaccinia); however, there are exceptions. Rhinoviruses are a frequent target for chemotherapy, but no small animal rhinovirus infection is available for use. Other non-respiratory picornavirus infections can be produced in mice, but they have questionable application. Antiviral activity may be selective among the picornavirus group as illustrated in Table 9 for a number of compounds with plaque inhibition activity against $4 / 4$ rhinoviruses in vitro. Circumventing these animal models in the development of compounds with rhinovirus activity is arduous, but feasible ${ }^{144}$. With rhinovirus interest firmly established by qualitative and quantitative in vitro techniques, metabolic studies can largely define the potential for absorption, stability, and appropriate tissue distribution, concentration and retention. Furthermore, subclinical rhinovirus upper respiratory infections can be produced in chimpanzees and gibbons ${ }^{145,146}$. These systems can be used for evaluation of selected compounds with the effect measured in terms of viral isolation

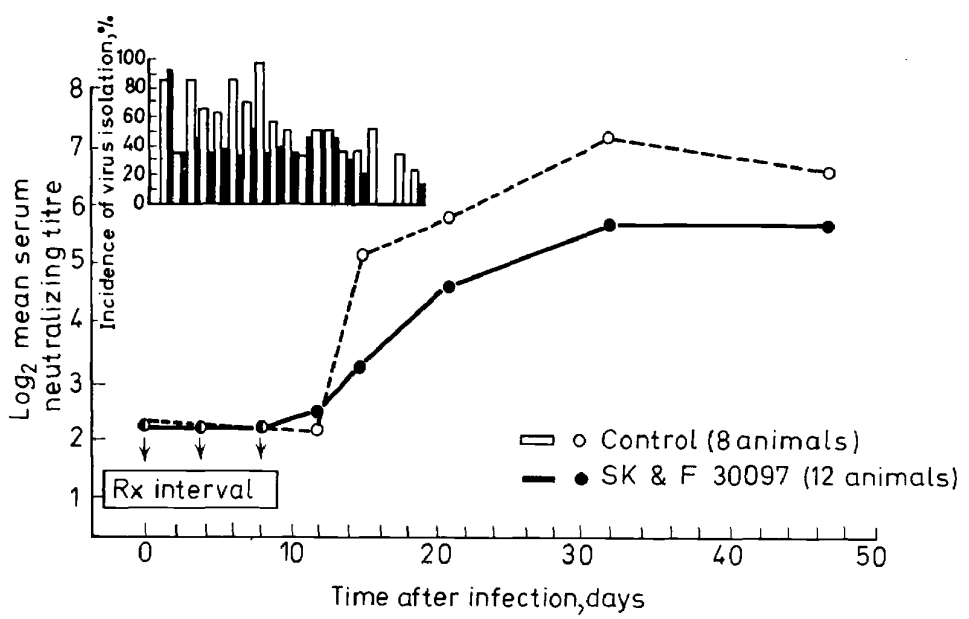

Figure 19. Effect of SK \& F 30097 on virus isolation and seroconversion in chimpanzees infected with rhinovirus 14 (pretreatment).

from nasal secretion, and by antibody response, as illustrated for an experimental compound in Figure 19. In this example, the compound produced an apparent, but not significant, reduction in both incidence of virus shedding and seroconversion.

\section{Market areas}

The cost of a directed antiviral screening effort is exceedingly great. Promising compounds must be subsequently evaluated for toxicity and then tested extensively in the clinic. Few compounds have been or will be marketed relative to input. A careful assessment of need, probable usage and feasibility must, therefore, be made for different disease areas. An ideal compound would have clear therapeutic utility against a prevalent (preferably serious) disease syndrome, be essentially non-toxic, and readily available at low cost. 
Many diseases of known or suspected viral aetiology are candidates for a compound with such a profile. Serious problems arise short of this goal. The marketability of a therapeutic agent diminishes with disease incidence, though seriousness counterbalances this equation.

Chemoprophylaxis is attractive in the absence of an adequate vaccine provided (1) the disease has high incidence, (2) occurs in recognizable epidemics and (3) sensitive viruses are predominantly responsible. This situation potentially applies to influenza and the common cold. With sufficiently broad activity (i.e. influenza A and B, para-influenzas and rhinoviruses) a prophylactic agent could be useful in respiratory disease seasons in the absence of epidemics.

\section{Spectrum of activity}

Antiviral agents are frequently considered to have narrow spectra of activity. Several striking examples already cited are cases to point. These do not necessarily foretell the future, however. Experimental compounds. albeit with certain liabilities, exhibit intrinsic antiviral activity against a wide

Table 10. Antiviral spectrum of SK\&F 30097 in vitro.

\begin{tabular}{ll}
\hline Adeno (types 3, 7) & Polio (types 1-3) \\
Coxsackie A (type 21) & Pseudorabies \\
Coxsackie B (types 1-6) & Rhino (19 strains) \\
Cytomegalo (3 strains) & Semliki Forest \\
EB & Vaccinia \\
Herpes simplex &
\end{tabular}

spectrum of viruses in the laboratory. SK\&F 30097 is such an example (Table 10). Possibly other compounds will exhibit such a breadth of activity in vivo.

\section{E. Therapeutic potential}

Without exception, prophylaxis is more attainable with antiviral compounds than is therapy. This conclusion is based on experience as well as on the kinetics of viral disease relative to replication of the aetiologic agent. Disease, usually measured by pathology, is frequently first observed when peak viral titres are attained. Caution must be applied in the extrapolation of such data, however: (1) the pathogenesis of viral disease varies widely, and that of human disease is rarely well-known, (2) pathology is not synonymous with symptomatology - the latter undoubtedly appears earlier, and (3) peak titres represent a balance between continued viral replication and the inactivation and removal of the agent; considerable, and possibly critical, amounts of viral material are synthesized after this time.

Diseases with a slow course of development are undoubtedly the better candidates for therapy. However, even acute conditions have been shown amenable to treatment well after initiation of viral replication as illustrated by clinical data with amantadine and idoxuridine and by the following example using hyperimmune serum against influenza A/PR8 in mice (Figure $20)^{83}$. Approximately $240 \mathrm{HI}$ units of antiserum prepared against influenza 


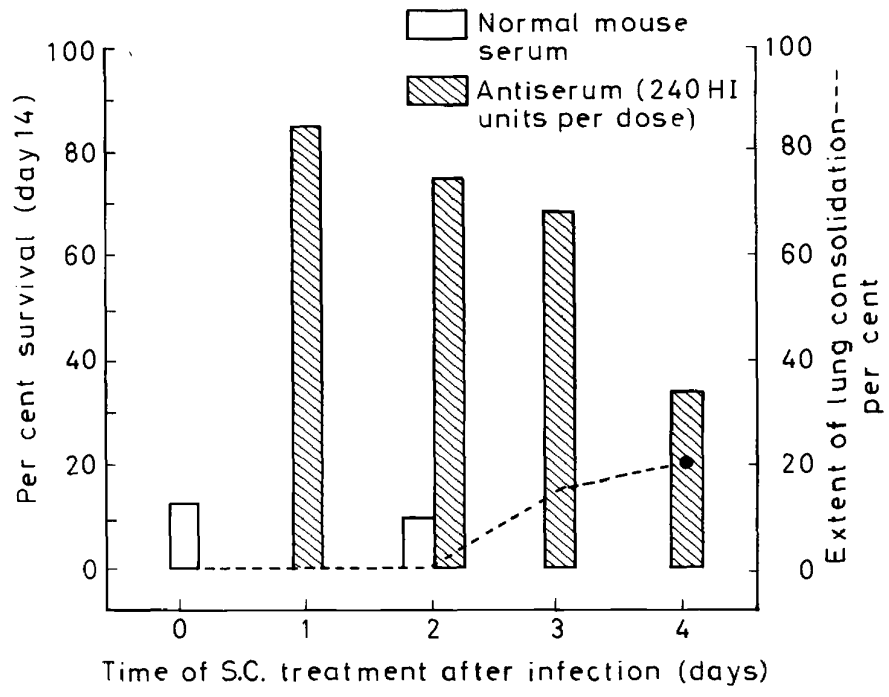

Figure 20. Therapeutic effect of antiserum against influenza A/PR8 mouse pneumonitis.

A/PR8 in mice were injected subcutaneously at the indicated times in relation to infection with an $\mathrm{LD}_{90}$ of virus. Although activity diminished with delay in treatment, a significant protective effect was still observed when the antiserum was first applied $72 \mathrm{~h}$ after infection.

In conclusion, the status of viral chemotherapy may be likened to that of the early sulphonamide era in bacteriology. Clinically active compounds are available and feasibility for more effective applications is established.

\section{REFERENCES}

1 E. C. Herrman. Proc. Soc. Exptl. Biol. Med. 107, 142 (1961).

2 R. J. Huebner, W. T. Lane, A. D. Welch, P. Calabresi, R. W. McCollum and W. H. Prusoff. Science 142, 488 (1963).

3 H. E. Kaufman, A. B. Newburn and E. D. Maloney. Virology 18, 567 (1962).

4 H. E. Kaufman. Proc. Soc. Exptl. Biol. Med. 109, 251 (1962).

5 E. E. Force, R. C. Stewart and R. F. Haff. Virology 23, 363 (1964).

6 A. H. Tomlinson and F. O. MacCallum. Brit. J. Exptl. Pathol. 49, 277 (1968).

7 E. E. Force and R. C. Stewart. J. Immunol. 93, 872 (1964).

8 E. E. Force and R. C. Stewart. Proc. Soc. Exptl. Biol: Med. 116, 803 (1964).

9 H. E. Kaufman, A. B. Newburn and E. D. Maloney. Arch. Ophthalmol. 67, 583 (1962).

10 J. A. Gold, R. C. Stewart and J. McKee. Ann. N.Y. Acad. Sci. 130, 209 (1965).

11 E. E. Force. Personal communication, February 1964.

12 F. O. MacCallum and B. E. Juel-Jensen. Brit. Med. J. 2, 805 (1966).

13 H. C. W. Stringer. New Zeal. Med. J. 30, 317 (1969).

14 B. E. Juel-Jensen. Ann. N.Y. Acad. Sci. 173, 74 (1970).

15 E. L. Charnock and H. G. Cramblett. J. Pediat. 76, 459 (1970).

16 E. W. Delamore and W. H. Prusoff. Biochem. Pharmacol. 11, 101 (1962).

17 S. Kit and D. R. Dubbs. Biochem. Biophys. Res. Commun. 22, 55 (1963).

18 H. E. Kaufman. Invest. Ophthalmol. 2, 504 (1963).

19 H. E. Kaufman and E. D. Maloney. Arch. Ophthalmol. 69, 626 (1963).

20 H. E. Kaufman. Ann. N.Y. Acad. Sci. 130, 168 (1965). 


\section{RICHARD F. HAFF}

21 M. M. Nemes and M. R. Hilleman. Proc. Soc. Exptl. Biol. Med. 119, 515 (1965).

22 H. E. Kaufman and C. Heidelberger. Science 145, 585 (1964).

23 M. Privat de Garilhe and J. DeRudder. C.R. Acad. Sci, Paris, 259, 2725 (1964).

${ }^{24}$ F. A. Miller, G. J. Dixon, J. Ehrlich, B. J. Sioan and I. W. McLean, Jr. Antimicrobial Agents Chemotherapy p. $136(1968)$.

${ }^{25}$ R. W. Sidwell, G. J. Dixon, F. M. Schabel, Jr. and D. H. Kaump. Antimicrobial Agents Chemotherapy p. 148 (1968).

26 B. J. Sloan, F. A. Miller, J. Ehrlich, I. W. McLean and H. E: Machamer. Antimicrobial Agents Chemotherapy p. 161 (1968).

${ }^{27}$ G. J. Dixon, R. W. Sidwell, F. A. Miller and B. J. Sloan. Antimicrobial Agents Chemotherapy p. 172(1968).

28 D. Hamre, J. Bernstein and R. Donovick. Proc. Soc. Exptl. Biol. Med. 73, 275 (1950).

29 R. L. Thompson, S. A. Minton, J. E. Officer and G. H. Hitchings. J. Immunol. 70, 229 (1953).

30 D. J. Bauer and P. W. Sadler. Brit. J. Pharmacol. 15, 101 (1960).

31 J. M. Z. Gladych, J. H. Hunt, D. Jack, R. F. Haff, J. J. Boyle, R. C. Stewart and R. J. Ferlauto. Nature 221, 286(1969).

32 D. J. Bauer, K. Apostolov and J. W. T. Selway. Ann. N.Y. Acad. Sci. 173, 314 (1970).

${ }^{33}$ D. J. Bauer and K. Apostolov. Science 154, 796 (1966).

34 D. J. Bauer and P. W. Sadler. Lancet 1, $1110(1960)$.

35 D. J. Bauer and F. W. Sheffield. Nature 184, 1496 (1959).

${ }^{36}$ D. J. Bauer, K. R. Dumbell, P. Fox-Hulme and P. W. Sadler. Bull. World Health Organ. 26, $727(1962)$.

37 D. J. Bauer, L. St. Vincent, C. H. Kempe and A. W. Downie. Lancet 2, 494 (1963).

38 D. J. Bauer. Ann. N.Y. Acad. Sci. 130, 110 (1965).

39 L. A. Ribeiro Do Valle, P. Raposo De Melo, L. F. De Salles Gomes and L. Morato Proenca. Lancet 2, 976 (1965).

40 B. R. Adels and T. E. Oppé. Lancet 1, 18 (1966).

41 A. J. E. Barlow. Brit. Med. J. 1, 1144 (1962).

42 B. Jaroszynska-Weinberger. Arch. Disease Childhood 45, 573 (1970).

43 C. H. Kempe. In First International Conference on Vaccines Against Viral and Rickettsial Diseases of Man, Washington, D.C., 1966 (Pan American Sanitary Bureau, Publications, No. 147), Pan American Health Organization: Washington, D.C. (1967).

44 D. Mainwaring. Brit. Med.J. 1, 1412 (1962).

45 W. Turner, D. J. Bauer and R. H. Nimmo-Smith. Brit. Med. J. 1, 13.17 (1962).

${ }^{46}$ K. B. Easterbrook. Virology 17, 245 (1962).

47 B. Woodson and W. K. Joklik. Proc. Natl. Acad. Sci. US 54, 946 (1965).

48 J. A. Holowczak and W. K. Joklik. Virology 33, 726 (1967).

49 W. K. Joklik and Y. Becker. J. Mol. Biol. 10, 452 (1964).

50 G. Appleyard, V. B. M. Hume and J. C. N. Westwood. Ann: N.Y. Acad. Sci. 130, 92 (1965).

51 A. R. Rao, J. A. MacFadzean and S. Squires. Ann. N.Y. Acad. Sci. 130, 118 (1965).

52 A. R. Rao, J. A. MacFadzean and K. Kamalakshi. Lancet 1, 1068 (1966).

53 W. L. Davies, R. R. Grunert, R. F. Haff, J. W. McGahen, E. M. Neumayer, M. Paulshock, J. C. Watts, T. R. Wood, E. C. Hermann and C. E. Hoffmann. Science 144, 862 (1964).

54 E. M. Neumayer, R. F. Haff and C. E. Hoffmann. Proc. Soc. Exptl. Biol Med. 119, 393 (1965).

55 F. J. Stanfield and R. F. Haff. Unpublished.

56 N. Kato and H. Eggers. Virology 37, 632 (1969).

57 H. F. Maassab and K. W. Cochran. Science 145, 1443 (1964).

58 A. W. McClurkin and J. O. Norman. Can. J. Comp. Med. Vet. Sci. 31, 299 (1967).

59 A. M. Wallbank, R. E. Matter and N. G. Klinikowski. Science 152, $1760(1966)$.

${ }^{60}$ R. R. Grunert, J. W. McGahen and W. L. Davies. Virology 26, 262 (1965).

61 J. T. Bryans, W. W. Zent, R. R. Grunert and D. C. Boughton. Nature 212, 1542 (1966).

62 K. W. Cochran, H. F. Maassab, A. Tsunoda and B. S. Berlin. Ann. N.Y. Acad. Sci. 130, 432 (1965).

${ }^{63}$ G. G. Jackson, R. E. Muldoon and L. W. Akers. Antimicrobial Agents Chemotherapy 3, 703 (1963).

${ }^{64}$ E. D. Stanley, R. L. Muldoon, L. W. Akers and G. G. Jackson. Ann. N.Y. Acad. Sci. 130, 44 (1965).

65 D. A. J. Tyrrell, M. L. Bynoe and B. Hoorn. Brit. J. Exptl. Pathol. 46, 370 (1965).

66 Y. Togo, R. B. Hornick and A. T. Dawkins, Jr. J. Am. Med. Assoc. 203, 87 (1968). 


\section{PROBLEMS AND PROGRESS IN VIRAL CHEMOTHERAPY}

67 A. A. Smorodintsev, D. M. Zlydnikov, A. M. Kiseleva, J. A. Romandv, A. P. Kazantsev and V. I. Rumovsky. J. Am. Med. Assoc. 213, 1448 (1970).

68 H. A. Wendel, M. T. Snyder and S. Pell. Clin. Pharmacol. Therap. 7.38 (1966).

69 J. J. Quilligan, Jr., M. Hirayama and H. D. Baernsterin, Jr. J. Pediat. 69, 572 (1966).

${ }^{70}$ J. F. Finklea, A. V. Hennessy and F. M. Davenport. Am. J. Epidemiol. 85, 403 (1967).

71 A. W. Galbraith, J. S. Oxford, G. C. Schild and G. I. Watson. Lancet 1, 1026 (1969).

72 A. A. Smorodintsev, G. L. Karpuchin, D. M. Zlydnikov, A. M. Malysheva, E. G. Shvetsova, S. A. Burov, L. M. Chramtsova, Y. A. Romanov, L. Y. Taros, Y. G. Ivannikov and S. D. Novoselov. Ann. N.Y. Acad. Sci. 173, 44 (1970).

73 A. Floor-Wieringa, H. Geuens and R. Van Strik. Proc. 5th Intern. Congr. Chemotherapy Vienna 4, 333(1967).

${ }^{74}$ N. Oker-Blom, T. Hovi, P. Leinikki, T. Palosuo, R. Pettersson and J. Suni. Brit, Med. J. 3, 676 (1970).

75 A. B. Sabin. J. Am. Med. Assoc. 200, 135 (1967).

76 E. T. Tyler and W. B. Kessler. Symp. on Aspects of Antiviral Therapy at E. I. duPont de Nemours \& Co.: Wilmington, Delaware, October 22-23, 1964.

77 J. A. Schneider, D. G. Iezzoni and S. A. Mahler. Ann. N.Y. Acad. Sci. 173, 103 (1970).

78 G. G. Jackson, E. D. Stanley and R. L. Muldoon. 1st Int. Conf. on Vaccines Against Viral and Rickettsial Diseases of Man. World Health Org. Sci. Public. No. 147. p. 595 (1967).

79 Y. Togo, R. B. Hornick, V. J. Felitti, M. L. Kaufman, A. T. Dawkins, Jr., V. E. Kilpe and J. L. Claghorn. J. Am. Med. Assoc. 211, 1149 (1970).

80 W. L. Wingfield, D. Pollack and R. R. Grunert. New Eng. J. Med. 281, 579.(1969).

81 V. Knight, D. Fedson, J. Baldini, R. G. Douglas and R. B. Couch. Infect. Immun. 1, 200 (1970).

82 C. E. Hoffmann, E. M. Neumayer, R. F. Haff and R. A. Goldsby. J. Bacteriol. 90,623 (1965).

83 W. B. Flagg, R. F. Haff and J. F. Pagano. Unpublished.

${ }^{84}$ W. B. Flagg, F. J. Stanfield, R. F. Haff, R. C. Stewart, R. J. Stedman, J. Gold and R. J. Ferlauto. Antimicrobiol Agents Chernotherapy p. 194 (1968).

85 C. A. Pinto and R. F. Haff. Antimicrobial Agents Chemotherapy p. 201 (1968).

86 A. Peters, C. A. DeBock, G. B. Paerels and J. L. M. A. Schlatmann, Progress in Antimicrobial Chemotherapy p. 71 University of Tokyo: Tokyo (1970).

87 A. Tsunoda, H. F. Maassab, K. W. Cochran and W. C. Eveland, Antimicrobial Agents Chemotherapy p. 553 (1965).

88 J. W. McGahen, E. M. Neumayer, R. R. Grunert and C. E. Hoffmann, Ann. N.Y. Acad. Sci. 173, $557(1970)$.

89 A. T. Dawkins, Jr., L. R. Gallager, Y. Togo, R. B. Hornick and B. A. Harris, J. Am. Med. Assoc. 203, 93 (1968).

90 S. Rabinovich, J. T. Baldini and R. Bannister, Am. J. Med. Sci. 257, 328 (1969).

91 A. Isaacs and J. Lindenmann. Proc. Roy. Soc. London Ser. B. 147, 258 (1957).

92 H. M. Powell, C. G. Culbertson, J. M. McGuire, M. M. Hoehn and L. A. Baker. Antibiot. Chemotherapy 2, 432 (1952).

93 R. E. Shope. J. Exptl. Med. 97, 601 (1953).

94 T. C. Merigan, ed. Symposium on Interferon and Host Response to Virus Infection. Arch. Internal Med. $126(1970)$.

95 J. Vilcek (ed.). Interferon. Springer-Verlag: New York (1969).

96 E. Falcoff, R. Falcoff, F. Fournier and C. Chany. Ann. Inst. Pasteur 111, 562 (1966).

97 K. Cantell. H. Strander, G. Hadhazy and H. R. Nevanlinna. In G. Rita, ed. The Interferons. p. 223. Academic Press, New York (1968).

98 I. Gresser. Proc. Soc. Exptl. Biol. Med. 108, 799 (1961).

99 C. A Pinto, R. F: Haff, J. R. Valenta, J. F. Pagano, C. J. DiCuollo and R. J. Ferlauto. Symp. Series Immunobiol. Standard 14, 105, Karger: Basel and New York (1970).

100 R. D. Andrews, G. Appleyard, A. J. Beale, R. A. Bucknall, K. Cantell, M. Clarke, E. M. B. Clements, C. C. Draper, K. H. Fantes, N. B. Finter, H. Nevanlinna, F. T. Perkins, D. A. J. Tyrrell and A. Whittaker. Ann. N.Y. Acad. Sci. 178, 770 (1970).

101 Scientific Committee on Interferon. Lancet 1, 873 (1962).

102 B. R. Jones, J. E. K. Galbraith and M. K. Al-Hussaini. Lancet 1, 875 (1962).

103 T. Kishida, J. Imanishi, A. Toida and M. Natsuaki. Personal communication, June 1970.

104 V. D. Solov'ev. Bull. World Health Organ. 41, 683 (1969).

105 D. A. Buthala, R. Damiano and E. E. Eidson. Ann. N.Y. Acad. Sci. 173, 794 (1970).

106 Scientific Committee on Interferon. Lancet 1. 505 (1965). 


\section{RICHARD F. HAFF}

107 R. F. Krueger and G. D. Mayer. Science 169, 1213 (1970).

108 L. F. Ellis and W. J. Kleinschmidt. Nature 215, 649 (1967).

109 G. T. Banks, K. W. Buck, E. B. Chain, F. Himmelweit, J. E. Marks, J. M. Tyler, M. Hollings, F. T. Last and O. M. Stone. Nature 218, 542 (1968).

110 W. J. Kleinschmidt, L. F. Ellis, R. M. Van Frank and E. B. Murphy. Nature 220, 167 (1968).

111 G. P. Lampson, A. A. Tytell, A. K. Field, M. M. Nemes and M. R. Hilleman. Proc. Natl. Acad. Sci. US 58, 782 (1967).

112 E. DeClercq and P. DeSomer. Proc. Soc. Exptl. Biol. Med. 132, 699 (1969).

113 D. N. Planterose, P. J. Birch, D. J. F. Pilch and T. J. Sharpe. Nature 227, 504(1970).

114 G. T. Banks, K. W. Buck, E. B. Chain, J. E. Darbyshire, F. Himmelweit, G. Ratti, T. J. Sharpe and D. N. Planterose. Nature 227, 505 (1970).

115 A. Tsunoda and N. Ishida. Ann. N.Y. Acad. Sci. 173, 719 (1970).

116 A. K. Field, G. P. Lampson, A. A. Tytell, M. M. Nemes and M. R. Hilleman. Proc. Natl. Acad. Sci. US 58, 2102 (1967).

117 M. M. Nemes, A. A. Tytell, G. P. Lampson, A. K. Field and M. R. Hilleman. Proc. Soc. Exptl. Biol. Med. 132, 784 (1969).

118 A. K. Field, A. A. Tytell, G. P. Lampson and M. R. Hilleman, Proc. Natl. Acad. Sci. US 58, 1004 (1967).

119 M. Y. Goore, J. F. Naylor, L. R. Fare, J. R. Valenta, W: B. Flagg, R. F. Haff, C. J. Dicuollo, J. F. Pagano and R. J. Ferlauto. Symp. Series Immunobiol. Standard 14, 249. Karger: Basel and New York (1970).

120 A. Isaacs, R. A. Cox and Z. Rotem. Lancet 2, 113 (1963).

121 S. Baron, N. N. Bogomolova, A. Billian, H. B. Levy, C. E. Buckler, R. Stern and R. Naylor. Proc. Natl. Acad. Sci. US 64, 67 (1969).

122 P. Claes, A. Billiau, E. DeClercq, J. Desmyter, E. Schonne, H. Vanderhaeghe and P. DeSomer. J. Virol. 5, 313 (1970).

123 W. Regelson and O. Foltyn. Proc. Am. Assoc. Cancer Res. 7, 58 (1966).

124 R. R. Wagner, R. M. Snyder, E. W. Hook and C. N. Luttrell. J. Immunol. 83, 87 (1959).

125 E. DeClercq and P. DeSomer. Appl. Microbiol. 16, 1314 (1968).

126 P. E. Came, M. Lieberman, A. Pascale and G. Shimonaski. Proc. Soc. Exptl. Biol. Med. 131, 443 (1969).

127 C. A. Pinto, R. F. Haff and J. F. Pagano. Unpublished.

128 M. Worthington and S. Baron. Personal communication, September 1970.

129 M. Worthington and S. Baron. Personal communication, September 1970.

130 T. C. Merigan and W. Regelson. New Engl. J. Med. 277, 1283 (1967).

131 M. R. Hilleman. Arch. Internal Med. 126, 109 (1970).

132 D. A. Hill, S. Baron, H. B. Levy, J. Bellanti, C. E. Buckler, G. Cannellos, P. Carbone, R. M. Chanock, V. DeVita, M. A. Guggenheim, E. Homan, A. Z. Kapikian, R. L. Kirschstein, J. Mills, J. C. Perkins, J. E. VanKirk and M. Worthington. Personal communication, February, 1970.

133 J. D. Coombes, K. W. Brammer, R. H. Herbst-Laier, N. M. Larin, C. R. McDonald, M. S. Tute, E. A. Wickham and G. M. Williamson. Ann. N.Y. Acad. Sci. 173, 462 (1970).

134 A. S. Beare, M. L. Bynoe and D. A.' J. Tyrrell. Lancet 1, 843 (1968).

135 S. E. Reed, A. S. Beare, M. L. Bynoe and D. A. J. Tyrrell. Ann. N.Y. Acad. Sci. 173, 760 (1970).

136 P. N. Meenan and I. B. Hillary. Lancet 2, 614 (1969).

137 P. N. Meenan and I. B. Hillary. Lancet 2, 641 (1969).

${ }^{138}$ E. Dahlgren, T. Ericsson, A. Ivert, O. Karlberg. Y. Rigéus, N. Tolagen and B. Melander. 4th Intern. Congress Infect. Diseases p. 787 Schattaner-Verlag: Stuttgart (1966).

139 M. Kaji, S. Kamiya, E. Tatewaki, Z. Nagafuchi and N. Fujiware. Chemotherapy(Tokyo) 14, 66 (1966).

140 M. Kaji, S. Kamiya, N. Fujiware, J. Mitsuuchi and S. Hirayama. Chemotherapy (Tokyo) 14, 69 (1966).

141 G. G. Jackson, R. L. Muldoon, L. W. Akers, O. Liu, G. C. Johnson and C. Engle. Antimicrobial Agents Chemotherapy p. 883 (1961).

142 G. Meiklejohn, W. P. McCann and S. Shkolnik. Military Med. 128, 890 (1963).

143 D. A. Buthala. Ann. N.Y. Acad. Sci. 130, 17 (1965).

144 R. F. Haff. Progress in Antimicrobial and Anticancer Chemotherapy 2, 818. Univ. of Tokyo: Tokyo (1970).

145 E. C. Dick. Proc. Soc. Exptl. Biol. Med. 127, 1079 (1968).

146 C. A. Pinto and R. F. Haff. Nature 224, 1310 (1969). 